\title{
Migraciones entre lo local y lo regional en los Andes peruanos: redes rural-urbanas, fragmentaciones espaciales y recomposiciones identitarias
}

Migrations entre local et provincial dans les Andes péruviennes : réseaux ruraux-urbains, fragmentations spatiales et recompositions identitaires Migrations between local and provincial in the peruvian Andes: rural-urban networks, spatial fragmentations and identitarian recompositions

\section{OpenEdition Journals}

Edición electrónica

URL: http://journals.openedition.org/bifea/3734

DOI: $10.4000 /$ bifea.3734

ISSN: 2076-5827

Editor

Institut Français d'Études Andines

Edición impresa

Fecha de publicación: 1 diciembre 2007

Paginación: 427-445

ISSN: 0303-7495

Referencia electrónica

Jacques Malengreau, « Migraciones entre lo local y lo regional en los Andes peruanos: redes ruralurbanas, fragmentaciones espaciales y recomposiciones identitarias », Bulletin de I'Institut français d'études andines [En línea], 36 (3) | 2007, Publicado el 01 junio 2008, consultado el 01 diciembre 2020. URL : http://journals.openedition.org/bifea/3734 ; DOI : https://doi.org/10.4000/bifea.3734

Les contenus du Bulletin de l'Institut français d'études andines sont mis à disposition selon les termes de la licence Creative Commons Attribution - Pas d'Utilisation Commerciale - Pas de Modification 4.0 International. 


\title{
Migraciones entre lo local y lo regional en los Andes peruanos: redes rural- urbanas, fragmentaciones espaciales y recomposiciones identitarias*
}

\author{
Jacques Malengreau**
}

\begin{abstract}
Resumen
Este artículo trata de la reproducción y de la reconstrucción de redes y solidaridades sociales entre, por una parte, dos pueblos de los Andes peruanos, y por otra, los centros provinciales y regionales de implantación de los migrantes procedentes de esas dos localidades. El autor muestra a través de este análisis como, dentro de la misma generación de migrantes, pero también a un nivel intergeneracional, lejos de constituir una ruptura con el medio de origen o un escalón hacia centros más importantes como la capital nacional o el extranjero, las migraciones hacia los centros provinciales y regionales constituyen un acomodamiento del espacio originario sin modificación fundamental de este último. Lo hacen a través de una extensión y de una fragmentación del espacio originario social y territorial. Permiten también la reproducción de los dominios familiares hereditarios frente al aumento demográfico y construyen redes de acción social y económica rural-urbana a nivel regional, al mismo tiempo que debilitan al nivel local y rural las estructuras e identificaciones supradomésticas de tipo comunitario.
\end{abstract}

Palabras clave: migraciones andinas, centros regionales, redes familiares, grupos sociales, reestructuración espacial

\footnotetext{
Una forma preliminar de este trabajo fue presentada como ponencia al simposio ANT 51 Globalización y procesos culturales en los Andes: actores y estrategias, en el $52^{\circ}$ Congreso Internacional de los Americanistas, Sevilla, 17-21 de julio de 2006.

** Senior Investigador Asociado del Fondo Nacional de la Investigación Científica (Bélgica), Centro de Antropología Cultural (Instituto de Sociología), Universidad Libre de Bruselas. E-mail: jmalengr@ulb.ac.be
} 


\title{
Migrations entre local et provincial dans les Andes péruviennes : réseaux ruraux-urbains, fragmentations spatiales et recompositions identitaires
}

\author{
Résumé \\ Il est question dans ce travail de la reproduction et de la reconstruction des réseaux et des solidarités \\ sociales établies entre, d'une part, deux villages des Andes péruviennes et, d'autre part, les centres \\ provinciaux et régionaux d'implantation des migrants qui proviennent de ces deux localités. L'auteur \\ montre à travers cette analyse comment, au sein d'une même génération de migrants, mais également \\ à un niveau intergénérationnel, loin de constituer une rupture avec le milieu d'origine ou un étape \\ vers des centres plus importants comme la capitale nationale ou l'étranger, les migrations vers les \\ centres provinciaux et régionaux constituent un aménagement de l'espace originaire sans modification \\ fondamentale de ce dernier. Elles le font à travers une extension et une fragmentation de l'espace \\ originaire social et territorial. Elles autorisent également la reproduction des domaines familiaux \\ héréditaires face à la croissance démographique et construisent des réseaux d'action sociale et \\ économique rurale-urbaine au niveau régional, en même temps qu'elles affaiblissent au niveau local \\ et rural les structures et identifications supradomestiques de type communautaire.
}

Mots clés : migrations andines, centres régionaux, réseaux familiaux, groupes sociaux, restructuration spatiale

\section{Migrations between local and provincial in the peruvian Andes: rural-urban networks, spatial fragmentations and identitarian recompositions}

\begin{abstract}
This paper is about the reproduction and the transformation of social networks and solidarities established between on the one hand two villages of the Peruvian Andes and on the other hand provincial and regional centers of settling of migrants who proceed from both villages. The author shows through this analysis how, among one same generation of migrants, but also at an intergenerational level, far from being a break with the site of origin or a step towards more important centers as the capital of the nation or abroad, migrations to the provincial and regional centers constitute an accommodation of the original space without fundamental modification of the latter. They are performing this through at the same time an extension and a fragmentation of the social and territorial original entity. They allow also the reproduction of family domains facing the demographic growth and build networks of social and economic rural-urban action at the regional level, at the same time as they debilitate at the local and rural level the supradomestic structures and identifications of a communitarian type.
\end{abstract}

Key words: Andean migrations, regional centers, kin networks, social groups, spatial restructuration

Desde siglos atrás y desde antes de la invasión europea y de su integración a imperios externos, el mundo andino local ha sido integrado en conjuntos sociales y políticos más amplios de tipo jerarquizado, con desplazamientos frecuentes de sus representantes por distintos motivos políticos, económicos y militares. Al mismo tiempo, las familias que componían los pequeños universos locales construyeron un modelo de relación al medio ambiente accidentado en el que residían, que se estructuraba sobre el uso complementario 
de varios recursos potenciales. Pero, desde la segunda mitad del siglo veinte, las migraciones de sus habitantes se hicieron más numerosas y más duraderas, en una forma más independiente por parte de los componentes domésticos y hasta individuales de la sociedad aldeana y local. Eso es debido a factores complejos que no se pueden analizar en este artículo y que abarcan al aumento demográfico, la extensión de empresas económicas comercializadoras y las desigualdades sociales crecientes en que resulta, las influencias culturales exteriores y las nuevas aspiraciones en términos de consumo que acompañan a esos procesos. El artículo tiene como propósito preguntarse en qué medida las migraciones ligadas a esos fenómenos sociales implican reestructuraciones particulares en las relaciones entre los habitantes, incluyendo a los migrantes, en los universos sociales específicos en los cuales se identifican esos diferentes actores como en la configuración del espacio social rural urbano en que ellos se mueven a través de los movimientos migratorios. Escogí más específicamente como materia de observación el mundo aldeano de dos pueblos rurales andinos de regiones distintas del Perú y los centros regionales o provinciales a los cuales se dirigen los migrantes de esos dos pueblos. Uno de ellos es San Carlos, ubicado en la región de Chachapoyas en el norte, y el otro, Cusipata ubicado en la región de Cusco en el sur. Los dos medios se diferencian mayormente por ser el segundo de ellos parte de un mundo más centralizado y jerarquizado desde antes de la invasión europea así como un lugar de presión más aguda sobre los recursos y la tierra, y el agua en particular.

Desarrollo aquí una perspectiva comparatista tanto al considerar dos pueblos, ambos andinos pero diferentes en cuanto a su contexto sociológico e histórico1, para resaltar las eventuales particularidades de las migraciones intrarregionales en comparación con las migraciones hacia la capital que fueron objeto de mis anteriores investigaciones. Aproveché de este modo mis previas investigaciones más desarrolladas sobre esos dos pueblos y sus experiencias migratorias respectivas, para evitar las generalizaciones abusivas a las cuales nos puede llevar el análisis de perspectivas o casos aislados. A través de las diferencias observadas, puedo echar las bases de marcos analíticos y abrir pistas para investigaciones ulteriores a partir de materiales más completos que los que tenemos hoy día.

Se trata de determinar más precisamente en qué medida el movimiento migratorio de esos pueblos a centros regionales constituye una ruptura con el mundo de origen o al contrario una extensión, incluso transformadora de este hacia afuera, y cómo se reproducen y se transforman distintos niveles de la organización social del medio de origen por este movimiento. La tradición oficial evolucionista en el marco de una centralización de la organización social nos da la imagen preconcebida de un cambio continuo evolucionando en una forma gradual a partir del pueblo arrinconado a través de un clientelismo provincial hacia la capital del país y hasta los centros cosmopolitas más amplios del mundo. Varias investigaciones de científicos sociales han puesto de relieve formas de continuidad entre los polos de la migración. Pero esas investigaciones concentran su atención sobre las migraciones hacia la ciudad metropolitana y centralizadora de Lima y, en el caso de algunas de ellas, sobre un campo reducido y especializado de la actividad mayormente económica2. Me pregunto hasta qué punto se perpetúan los lazos sociales y de vecindarios así como los mecanismos solidarios del pueblo originario, a través de la migración a un lugar regional relativamente cercano, accesible y de alcance más familiar a los migrantes

1 Como lo hicieron Gölte \& Adams (1987) para las migraciones a Lima a partir de distintos pueblos serranos y costeños y Spedding \& Llanos (1999: 184-189) para las migraciones a La Paz a partir de un pueblo de la cordillera y otro de las yungas subtropicales.

2 Como es el caso, por ejemplo, de los trabajos de Steinhauf (1991) y Steinhauf \& Huber (1996) que tratan de los artesanos negociantes originarios de pueblos rurales del norte occidental del Perú. 
y a su entorno social. Las redes sociales construidas a partir de familias particulares hacia afuera de las comunidades locales, según lo que observan Rogers \& Vertovec (1995: 1823) en una forma comparativa y universal, y Degregori (2001: 147-150) o Gölte (2001: 119-122) para el caso de los inmigrantes andinos en la ciudad de Lima, no solamente se reproducen, sino que se extienden y toman nuevos aspectos que plantean el problema de las reconstrucciones de los universos de identificación y de actuación. De hecho, según esas observaciones, la proximidad espacial se desprende por lo menos parcialmente en la ciudad grande de la ascendencia común de un mismo pueblo originario, mientras la identificación social y solidaria se multiplica allí.

Analizaremos si y hasta qué punto las migraciones hacia los centros regionales se conforman a este esquema aplicable en el caso de las migraciones hacia lugares más centralizados y más alejados de los pueblos de origen ${ }^{3}$. Para eso, después de haber precisado la importancia relativa de las migraciones hacia centros secundarios, se analizará la estabilidad relativa de la residencia en los centros regionales en relación a la doble residencia de los polos de la migración, así como los lazos específicos mantenidos con el entorno social tanto en el pueblo de origen como en el centro de implantación. Veremos también si la discontinuidad territorial aparente corresponde a unas discrepancias de los proyectos de vida entre los migrantes y sus familiares y paisanos que quedaron en el pueblo, o si, como lo afirman Long \& Roberts (1984: 217-218), Alber (1999: 159-164) y Altamirano (1999: 150), y en particular en lo que se refiere a los artesanos negociantes estudiados por Steinhauf (1991) y Steinhauf \& Huber (1996), existe una complementariedad entre las actividades de los polos de emigración y de inmigración dentro de las redes de parentesco interdomésticas que se formaron entre esos polos. De esta forma se constituye un importante cuadro de seguridad y de repliegue en caso de fracaso en sus empresas, y más específicamente entre los pueblos rurales y los centros regionales próximos, que según Altamirano (1999: 150) reciben una cantidad creciente de migrantes del campo andino en sustitución a la migración hacia la capital.

Las fuentes empíricas de información que sirven de base al presente artículo son los trabajos etnográficos que he realizado en ambos pueblos entre fines de los años 1960 e inicios del siglo XXI, así como entrevistas dirigidas realizadas entre los migrantes y sus familias de ambos pueblos y en distintos lugares de inmigración entre los años 1996 y $2005^{4}$.

\section{1. ¿EL CENTRO REGIONAL COMO ETAPA O DESTINO DE LA MIGRACIÓN?}

Muchos emigrantes de ambos pueblos se orientan hacia centros provinciales o regionales. Así, cerca de la mitad de las personas entrevistadas en esos pueblos que tenían familiares fuera tenían un pariente cercano (de primer grado) establecido en un centro regional. Para los de Cusipata, más de las $2 / 3$ partes de los que habían radicado en centros provinciales lo eran en Cusco, los otros en Arequipa u otro centro. Para los de San Carlos, el $60 \%$ estaban en un centro regional. Esos se reparten casi por igual entre Chiclayo, la capital

3 Me refiero aquí como más adelante en el trabajo, a mis observaciones acerca de los migrantes de los dos pueblos referidos en Lima (Malengreau, 2004).

4 Participaron en esas encuestas unas alumnas de último año de antropología de la Pontificia Universidad Católica del Perú, Lucia Guerra, Ana María Falcón y Vanessa Rojas. Entre los migrantes en Lima han sido entrevistados 27 de Cusipata y 58 de San Carlos. Han sido entrevistados en los centros provinciales: 25 migrantes de Cusipata en Cusco, 23 migrantes de San Carlos en Chiclayo, 51 migrantes de San Carlos en Pedro Ruiz y 3 migrantes de San Carlos en Chachapoyas. No han sido tomado en cuenta las entrevistas que se hicieron en los valles tropicales de ambas regiones, ni tampoco las que se hicieron en los mismos pueblos. 
regional costeña del Norte, y Pedro Ruiz, un nuevo centro poblacional secundario. Este último se desarrolló en el fondo del valle próximo del río Utcubamba — sobre la principal vía de comunicación regional, donde se ubica también un colegio secundario que, en el caso de Cusipata, existe en el pueblo mismo- mientras unas pocas familias de San Carlos tenían un pariente establecido en forma permanente en Chachapoyas, la capital departamental. Fuera de esos residentes permanentes, esta ciudad atrae casi solamente a colegiales y estudiantes de enseñanza superior en pedagogía. Ellos no permanecen después en esta ciudad.

Los estudios secundarios en los centros regionales constituyen un motivo de emigración para muchos jóvenes de ambos pueblos al momento de su salida, en tanto esos centros no estén demasiado alejados del pueblo y permiten las visitas de retorno al pueblo durante el fin de semana, como es el caso de Cusco para Cusipata y Pedro Ruiz o Chachapoyas para San Carlos. Chiclayo queda más lejos de este último pueblo y atrae menos estudiantes. Sin embargo, la mayoría de los jóvenes emigrados de Cusipata cursaron la secundaria en el mismo colegio del pueblo, siendo pocos los que lo hacen en Cusco. En comparación, la mayoría de los sancarlinos que migraron estudiaron en el colegio secundario en el centro más cercano de Pedro Ruiz, y solamente una minoría de ellos en Chachapoyas. Varias mujeres sancarlinas que salieron antes de terminar sus estudios secundarios en Pedro Ruiz o en Chachapoyas, los concluyen también en Lima, combinando los estudios con el trabajo doméstico para el cual viajaron. Cusco constituye también un lugar de estudios superiores para la minoría de los cusipateños que llegan a este nivel de estudios, sobre todo en las ramas técnicas, que muchos, por falta de recursos, no terminan. Chachapoyas juega ese papel en la formación pedagógica para lo(a)s sancarlino(a)s. Estos se dirigen a Lima para seguir otras formaciones superiores, mientras pocos cusipateños se dirigen a Lima para estudios superiores. Como lo anoté en un trabajo anterior (Malengreau, 2004), si el primer motivo que da inicio a la migración de los hombres sancarlinos hacia Lima es cursar estudios superiores, el trabajo constituye el primer motivo de migración a la capital para los cusipateños.

Pero de todas formas, y fuera del caso de la inmigración de los sancarlinos en Pedro Ruiz, ejercer una actividad lucrativa permanente en el centro de inmigración predomina como motivación en el caso de la mayoría de los migrantes hacia los centros regionales en general. Considerando las actividades reales del conjunto de los migrantes de ambos pueblos que están establecidos en los centros regionales, se puede observar que los centros regionales importantes, como Cusco para Cusipata en el sur o Chiclayo para San Carlos en el norte, sirven efectivamente antes que todo y para ambos pueblos de lugar de trabajo. El perfil ocupacional de los migrantes de ambos pueblos en los centros provinciales no cambia mucho con el de Lima. Entre los hombres cusipateños siempre predominan claramente, más o menos en un $80 \%$, los pequeños negociantes o artesanos independientes; el resto trabaja como obreros en la construcción de edificios o de carreteras. El $50 \%$ de los sancarlinos son asalariados, muchos con educación superior, empleados estatales en la enseñanza o en las fuerzas armadas (policía y, en menor medida, ejército), y los otros $50 \%$ son pequeños empresarios, especialmente en artesanía. Así que, los hombres emigrantes de San Carlos trabajan más a menudo que los de Cusipata como asalariados o empleados públicos, mientras los cusipateños trabajan más como independientes. Los sancarlinos tienen también una formación escolar algo superior a la de los cusipateños. En cuanto a las mujeres de ambos pueblos en los distintos centros de inmigración, las más jóvenes, muy a menudo empiezan con empleos domésticos. En el caso de las sancarlinas, combinan a menudo este oficio con la culminación de estudios secundarias, antes de casarse. Luego la mayoría de ellas combinan el trabajo en su casa con pequeños negocios independientes. Hay que anotar también que varios hombres sancarlinos, establecidos en Pedro Ruiz con 
el fin de permitir a sus hijos estudiar en el colegio, conservan en el pueblo de origen actividades agropecuarias con la ayuda de ellos, y combinándolas con nuevas actividades comerciales propias o de su esposa en su nuevo centro de residencia. Los cusipateños en Cusco, por su lado, cuando son jóvenes estudiantes, mayormente hombres, combinan sus estudios con varios trabajos temporales en esta ciudad, a la vez que siguen participando en las tareas familiares del campo en Cusipata durante los fines de semana.

Otro aspecto a destacar es que los centros regionales constituyen, en la gran mayoría de los casos, los destinos finales de la migración, sea directa o indirecta. Es decir, pocos vuelven a emigrar después a partir de los centros regionales, mientras más vuelven a salir de Lima. Eso se desprende del itinerario previo de los migrantes de ambos pueblos hacia cualquier centro de inmigración. De hecho, casi no se observa el uso de los centros regionales importantes donde se dirigen los migrantes de cada uno de los pueblos como trampolín para las migraciones hacia otros lugares, salvo en el caso de migrantes que realizaron estudios secundarios en esos centros para después migrar hacia Lima. Algunos cusipateños en Cusco expresan el deseo de volver a vivir en su pueblo con el fin de desarrollar allí un pequeño negocio o una pequeña empresa artesanal o agropecuaria. Pero pocos habitantes de Cusipata han vuelto efectivamente de un centro regional para establecerse permanentemente en el pueblo, tampoco en el caso de los migrantes conservando actividades en el pueblo. Más bien, los centros regionales constituyen a menudo un lugar de destino final de una migración que incluye etapas anteriores en centros más importantes, como otros centros regionales o Lima mismo. Esta etapa ha sido Lima, la capital, mayormente en el caso de obreros inestables, los empresarios independientes teniendo una residencia permanente en Lima. Ha sido un lugar de empleo rural de orientación comercial (plantaciones, trabajo en carreteras) en el caso de trabajadores manuales jornaleros o temporales; también ha sido un centro secundario de la región de origen en el caso de empleados públicos, más que todo profesores o policías. En los casos de docentes, el centro secundario sirve más a menudo como trampolín hacia otros centros regionales que hacia la capital.

Mientras más de las 2/3 partes de la migración de ambos pueblos en Lima es directa, la migración a los centros regionales - con la excepción de Pedro Ruiz para los sancarlinos, donde más del $60 \%$ de los migrantes no han permanecido en otro lugar-, a pesar de su mayor cercanía de los lugares de origen, solamente es efectiva para menos de la mitad de los migrantes cusipateños en Cusco y menos de la cuarta parte de los migrantes sancarlinos en Chiclayo.

Por lo menos, la cuarta parte de los migrantes de Cusipata establecidos en Cusco (en su mayoría hombres) han ejercido en forma repetida y desde su adolescencia trabajos temporales o estacionales como jornaleros en los valles tropicales vecinos. Los otros cusipateños establecidos en Cusco estuvieron en Lima, Arequipa, y en una menor medida, en otros centros secundarios, donde ocuparon empleos asalariados e inestables de baja calificación. Los migrantes indirectos de Cusipata a Cusco se reparten igualmente después de su llegada entre pequeños independientes y obreros asalariados o jornaleros.

Por su lado, las $3 / 4$ partes del total de los sancarlinos de Chiclayo permanecieron fuera de su pueblo en su mismo departamento de origen, y principalmente en Pedro Ruiz; pero la mayoría de ellos lo hicieron para estudiar allí en el colegio, residiendo en realidad entre Pedro Ruiz y San Carlos. Algunos se emplearon en Pedro Ruiz como pequeños artesanos y agricultores independientes para educar a sus hijos en el colegio, ocupando también antes de migrar a Chiclayo empleos estatales en la enseñanza o en el campamento militar cerca de Pedro Ruiz después de haber completado sus estudios. Un poco más de la mitad de los sancarlinos en Chiclayo residieron antes en Lima donde habían ocupado empleos asalariados poco calificados e inestables. Una tercera parte residieron anteriormente en los 
valles orientales. Conviene precisar que varias mujeres sancarlinas de Chiclayo trabajaron como empleadas domésticas en Lima, a veces terminando al mismo tiempo estudios secundarios en horarios especiales, sin lograr emplearse allí no más que en Chiclayo en una actividad especializada. Los hombres que se establecieron en Chiclayo después de haber residido en otro lugar, mayormente Lima, se reparten entre empleados públicos y pequeños empresarios independientes, estos últimos algo más calificados que los cusipateños en Cusco. Las mujeres sancarlinas que residieron en otro sitio fuera de su pueblo, cuando se establecen en Chiclayo donde siguieron mayormente a su esposo, se encargan más a menudo de su casa y llevan una actividad complementaria en un pequeño negocio independiente.

En Pedro Ruiz, la situación es algo distinta. Casi la mitad de los sancarlinos entrevistados en Pedro Ruiz ya habían residido en otro sitio fuera de su pueblo de origen, eso incluyendo por supuesto una etapa anterior en el mismo Pedro Ruiz. El 13 \% del total de los residentes sancarlinos en Pedro Ruiz radicaron en la capital departamental, Chachapoyas, la mayoría para realizar estudios superiores, y los pocos que trabajaron allí, lo hicieron ocupando empleos públicos. 16\% del total de los residentes sancarlinos en Pedro Ruiz vivieron en Lima, los hombres mayormente ejerciendo pequeños trabajos asalariados de baja calificación y en menor medida estudios superiores, y las mujeres ocupando empleos domésticos. Cerca del $60 \%$ de los que se establecieron en Pedro Ruiz después de haber residido afuera son empleados públicos o retirados de tal empleo; los $40 \%$ restantes trabajan como pequeños independientes en el negocio o en una artesanía. Algunos de los que migraron en otro lugar anteriormente combinan en Pedro Ruiz el producto de su actividad o de derechos de jubilación con alguna actividad agropecuaria en las cercanías que pertenecen al territorio de su comunidad de origen, San Carlos.

Cuadro 1 - \% de migrantes entre los polos mencionados que migraron sin etapa

$\begin{array}{ll}70 & \text { de Cusipata a Lima } \\ 72 & \text { de San Carlos a Lima } \\ 44 & \text { de Cusipata a Cusco } \\ 22 & \text { de San Carlos a Chiclayo } \\ 61 & \text { de San Carlos a Pedro Ruiz }\end{array}$

Cuadro 2 - \% de migrantes que hicieron etapa en los lugares mencionados 5 antes de llegar a su destino en el momento de la entrevista

Entre los cusipateños en Lima $\quad 04 \quad$ en los valles tropicales

00 en Lima

04 en Arequipa

19 en Cusco

04 en otros lugares

5 Los porcentajes son cumulativos: el $32 \%$ de los migrantes establecidos residieron en más de un lugar antes de llegar al lugar donde permanecían en el momento de la encuesta. 


$\begin{array}{lll}\text { Entre los sancarlinos en Lima } & 07 & \text { en los valles tropicales } \\ & 00 & \text { en Lima } \\ & 01 & \text { en Chiclayo } \\ \text { Entre los cusipateños en Cusco } & 24 & \text { en Chachapoyas } \\ & 16 & \text { en los valles tropicales } \\ & 16 & \text { en Arequipa } \\ & 06 & \text { en Cusco } \\ \text { Entre los sancarlinos en Chiclayo } & 12 & \text { en otros áreas rurales } \\ & 38 & \text { en los valles tropicales } \\ & 55 & \text { en Lima } \\ & 28 & \text { en Chachapoyas } \\ & 72 & \text { en Pedro Ruiz } \\ & 22 & \text { en otro lugar } \\ & & \\ \text { Entre los sancarlinos en Pedro Ruiz } & 02 & \text { en los valles tropicales } \\ & 16 & \text { en Lima } \\ & 02 & \text { en Chiclayo } \\ & 14 & \text { en Chachapoyas } \\ & 02 & \text { en Pedro Ruiz } \\ & 10 & \text { en otro área rural }\end{array}$

\section{LAZOS Y DISTANCIAMIENTOS ENTRE EL MUNDO CITADINO REGIONAL Y EL PUEBLO RURAL A TRAVÉS DE LAS MIGRACIONES}

Los centros regionales reciben más a menudo que Lima la visita de los parientes rurales cercanos de los migrantes. Esos parientes están así más familiarizados con el medio citadino regional que con Lima. Se van a los centros regionales sobre todo para visitar hijo(a)s todavía jóvenes y poco estabilizado(a)s, o son traídos por hijo(a)s mayores mayormente para ser curados cuando son ancianos, enfermos y sin hijo(a)s para encargarse de ellos en el pueblo mismo. A Lima van por motivos similares, pero más ocasionalmente y por periodos más largos. Los migrantes visitan a sus parientes en el pueblo de manera muy regular, en la mayoría de los casos de los migrantes cusipateños en Cusco, semanal o mensualmente; y semanalmente en el caso de los sancarlinos establecidos en Pedro Ruiz. Por su lado los migrantes de ambos pueblos establecidos en Lima se quedan durante varios años sin visitar a sus parientes en el pueblo. Los migrantes sancarlinos en Chiclayo, a un día de viaje de San Carlos, visitan menos aún a sus parientes en su pueblo de origen que los migrantes de su mismo pueblo en Lima, y — desde luego- que los cusipateños establecidos en Cusco. En comparación con sus paisanos de Lima, los sancarlinos en Chiclayo tienen en general recursos más limitados. Comparándolos con los cusipateños de Cusco, su mayor alejamiento residencial en relación con el pueblo de origen no facilita la suspensión de sus tareas laborales en Chiclayo. En todo caso, como en el ejemplo de las relaciones entre Lima y el pueblo rural, las visitas temporales entre los migrantes de ambos pueblos en los centros regionales y sus parientes del pueblo de origen se hacen en la mayoría de las veces cuando los hijos emigrados visitan a sus padres que residen en el pueblo, o entre hermano(a)s en ambos sentidos en el caso de haber fallecido los padres. Estas visitas temporales deben ser 
diferenciadas de los desplazamientos duraderos que hacen alguno(a)s del pueblo a sus hermano(a)s mayores de la ciudad o que hacen los o las sobrino(a)s del campo a sus tío(a)s residentes permanentes en un centro urbano, sea este regional o capitalino. En este último caso, la relación entre hermano(a)s es predominante, directamente o entre una persona y el o la hijo(a) de su hermano(a). En el marco de estas relaciones, un padre o una madre del pueblo manda ayuda, muchas veces en forma de alimentos del pueblo a su hijo(a) o a su hermano(a) de la ciudad que, por su parte, les retribuye alojando y alimentando en su casa a su hermano(a) menor o a su sobrino(a) mientras este último(a) estudia, busca un trabajo o es empleado(a) como aprendiz donde su hermano(a) mayor o su tío(a) en la ciudad. Las visitas de un poblador rural a un hermano(a) en la ciudad corresponden más a menudo a la visita a un(a) hijo(a) que reside donde el (la) hermano(a). Como los migrantes tienen hermano(a)s en el pueblo, en la generación siguiente, esos migrantes recibirán a su vez como tío(a) a los hijo(a) de sus hermano(a)s que permanecieron en el pueblo. Esta relación tío(a)-sobrino(a) constituye entonces una red transgeneracional de descendencia colateral dentro de la ciudad, tanto regional como capitalina, que se añade a la relación dentro del pueblo rural entre padre e hijo permaneciendo en el pueblo y a las relaciones rural-urbanas transgeneracionales directas entre padres del campo e hijos de la ciudad y rural-urbanas intrageneracionales entre hermano(a)s esparcidos en el espacio.

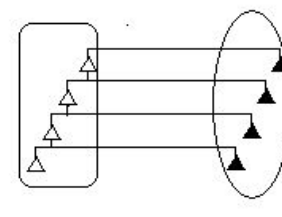

$$
\begin{aligned}
& \text { Leyenda } \\
& \text { lazo paterno rural } \\
& \text { lazo avuncular urbano } \\
& \text { lazo entre hermanos nural urbano } \\
& \text { lazo paterno rural urbano }
\end{aligned}
$$

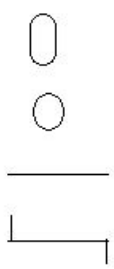

Figura 1 - Redes parentales entre campo
y ciudad

Las relaciones entre pueblo y centro regional ocurren más a través de desplazamientos personales con regalos, mientras que entre Lima y los pueblos se hacen más por intercambios de encomiendas. Las relaciones entre los parientes repartidos entre los pueblos y los centros regionales son más intensas e implican una complementariedad más flexible entre los productos de la actividad, inclusive alimenticios, específicos a cada uno de los lugares de residencia y a cada momento. Existe también un consumo alimenticio más homogéneo o integrado entre campo y centro regional que en el caso de las redes sociales que abarcan a Lima.

Este consumo más cotidiano y más homogéneo entre ciudad y campo, combinando los productos agropecuarios domésticos y manufacturados o importados, se debe también en el caso de los cusipateños de Cusco como en el de los sancarlinos de Pedro Ruiz al hecho de que, al contrario de los migrantes de ambos pueblos en lugares más alejados, siguen de manera más o menos regular, ayudando a sus padres o en una forma más independiente, participando en tareas de producción y de transformación domésticas en el pueblo, donde se desplazan en forma bastante regular. El hecho - para varios de ellos - de tener proyectos futuros en su pueblo cercano de origen refuerza su afán por seguir participando en esas 
tareas, como también en las obligaciones extradomésticas y comunitarias, para no perder el derecho de acceder a la tierra comunal originaria.

Los migrantes de ambos pueblos expresan de hecho un fuerte apego a su tierra de origen, y muy raras veces aceptan la idea de abandonar sus terrenos, o peor, vender los terrenos de la familia, que los padres conservan en su mayor parte hasta el fin de sus vidas. Los ausentes encomiendan a sus hermano(a)s ayudar a sus padres a trabajar los terrenos familiares, tanto los que están todavía en poder de los padres como algunos que hubieran adquirido con anticipación de esos últimos; les dejan también aprovechar de esas tierras, esperando en cambio unos productos de los terrenos con motivo de sus visitas o como remesa ocasional. Pero este apego se debilita entre los sancarlinos emigrados en centros urbanos alejados, Chiclayo o Lima; ellos consideran más fácilmente la opción de la venta de su parte de la herencia en tierras, siquiera para pagar los servicios y los bienes a beneficio de sus padres ancianos en el pueblo. Esta actitud algo diferente frente a la tierra entre los migrantes de ambos pueblos radicados en centros alejados como Lima, Arequipa o Chiclayo está ligada a la presión mayor sobre las tierras cultivables en Cusipata, como también a una asociación más intensa de la tierra con los antepasados y familiares en Cusipata donde la endogamia es más fuerte (Malengreau, 2004: 193-194).

Varios cusipateños que permanecen y trabajan en Cusco mantienen un lazo bastante activo con las tierras familiares en su pueblo. Un 1/4 de ellos supervisan la explotación agrícola de sus parcelas, compartiendo a medias con sus padres o con sus hermanos del pueblo tanto la inversión en trabajo humana y en insumos como el beneficio en productos de su explotación. En este sistema, los residentes urbanos confían la mayor parte del trabajo y de la administración a los parientes del medio rural con quién se han asociado y que organizan el trabajo de los jornaleros en el campo; los migrantes, por su lado, aportan su propiedad, insumos y dinero para pagar peones y comida, y ocasionalmente dan una mano al trabajo6. Algunos hombres de Cusipata que residen en Cusco realizan ellos mismos algunas tareas agrícolas ocasionales en sus tierras de Cusipata que han dejado a cargo de un pariente; también, algunas mujeres jóvenes cusipateñas que residen en Cusco ayudan, a través de idas y vueltas regulares al pueblo, a su madre en la venta de comidas en los paraderos de vehículos, mercados locales o tiendas en el pueblo o en las cercanías de este último.

Por su lado, aproximadamente las $3 / 4$ partes de los sancarlinos que se mudaron a Pedro Ruiz siguen ejerciendo ellos mismos actividades agrícolas o de crianza, comerciales como de subsistencia en el territorio tradicional de la comunidad de San Carlos; lo hacen sobre todo en los alrededores de la nueva población de Pedro Ruiz, pero también en lugares más alejados y elevados del territorio montañoso de la comunidad. Combinan esas actividades con sus ocupaciones en Pedro Ruiz donde residen la mayor parte del tiempo. Suben a sus tierras del pueblo durante los fines de semana, pero a veces también durante la semana; lo hacen a veces por varios días alojando en casas rudimentarias de campo. Esta combinación de medios distintos de vida no existe sin tensiones sociales de los migrantes con los residentes del pueblo antiguo originario. Eso se debe a las crecientes diferenciaciones socioeconómicas y al debilitamiento ya mencionado de los lazos supradomésticos comunes de los residentes de ambos lugares. También, en tanto originarios y primeros pobladores de Pedro Ruiz, los sancarlinos que viven en esta población son percibidos como privilegiados por los que proceden de otros pueblos de la región y hasta de más allá.

6 Pedraza Valverde (1992: 114-115, 133-135), en su estudio sobre los migrantes regionales en Cusco, subraya el hecho de que muchos de ellos combinan sus tareas agrícolas con trabajos diversos de poca duración en la ciudad de Cusco, practicando unas idas y vueltas entre campo y ciudad, sin realmente establecerse en una forma permanente en Cusco y guardando su residencia principal en el pueblo. Es también el caso para varios de los cusipateños. 
Entre los migrantes de ambos pueblos en los centros regionales próximos mencionados, los intercambios alrededor del trabajo de la tierra se concentran entre padres y sus hijo(a)s emigrados en la medida en que los padres quedan en posesión de sus tierras, y entre hermano(a)s en la medida que ello(a)s se han posesionado de la herencia de los padres. Esas relaciones pueden extenderse a los tíos de los migrantes en el pueblo cuando los tíos se han quedado con las tierras de los abuelos de los migrantes o con los primos si heredaron de esas tierras. Esa extensión familiar parece presentarse más a menudo en el caso de Cusipata que en el caso de San Carlos por la presión y la sacralización más intensas de la tierra en Cusipata en su asociación con los antepasados. Por el grado más elevado de endogamia en Cusipata, abarca allí más aún a colaterales de padre y madre como a los parientes de las parejas de los migrantes7. La identificación entre territorio y ascendencia es más intensa en Cusipata.

El hecho de que varios cusipateños residentes en Cusco y la mayoría de los sancarlinos residentes en Pedro Ruiz siguen tratando más o menos directamente con las tierras familiares del pueblo paralelamente a su empleo urbano, permite a conjuntos familiares rurales-urbanas mantener una producción polivalente. Esta última combina actividades de subsistencia con actividades de carácter comercial o de servicio público, y eso a través de un movimiento pendular entre el pueblo originario y el centro regional cercano. Eso constituye una forma de seguridad y garantiza cierta cohesión social para los conjuntos interdomésticos rural-urbanos. En el caso del impacto de las migraciones a centros más alejados, como la capital Lima, las remesas urbanas en bienes manufacturados y en dinero refuerzan la dependencia de los parientes ancianos del pueblo originario frente a los mecanismos de mercado. En efecto, los parientes rurales reemplazan el recurso a la ayuda informal de sus hijos radicados en centros más alejados por la contratación de mano de obra entre sus paisanos en el pueblo, usando para ese propósito el dinero que les mandan esos mismos hijos. Esta monetarización de las relaciones, mayor en el caso de la migración a la capital, debilita el tejido solidario supradoméstico y comunitario8.

En el caso de ambos pueblos, entre los migrantes permanentes establecidos en los centros regionales, incluso en el nuevo centro cercano de Pedro Ruiz, pocos regresan definitivamente a su pueblo de origen, pues lo consideran mayormente como un fracaso social que solamente puede ser ocultado o contrabalanceado por unos proyectos personales

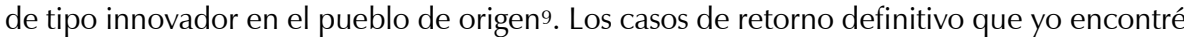
se dieron solamente después que los migrantes hayan permanecido pocos años o menos en el lugar de inmigración. Pero los retornos parecen convertirse en los últimos años en un hecho más común y ser menos desvalorizados.

Los retornantes sancarlinos definitivos se encuentran sobre todo entre les migrantes en Lima. Varios sancarlinos parecen no haber logrado su integración a la ciudad grande que constituye Lima. Parecen tener más dificultad que los cusipateños en adaptarse en

7 Ver Malengreau (1999: 128-130) donde se explica con gráfico el lazo entre matrimonios entre hijos de primos y sucesión bilateral de las tierras en el caso de San Carlos.

8 Sánchez et al. (1988) consideran que las migraciones, al sacar las personas más empredadores del campo y al implicar la encomienda de medios materiales a los parientes, posibilitando así su permanencia en el pueblo, refuerzan el conformismo y la pasividad en las áreas rurales. Esta afirmación, a pesar de atraer oportunamente la atención sobre el papel reproductor del medio rural que tiene las migraciones y las remesas, me parece entonces aplicarse más en el caso de las migraciones hacia lugares de centralización y alejados de los pueblos que hacia centros regionales próximos.

9 No tengo datos precisos sobre la cantidad de migrantes permanentes de ambos pueblos en los distintos lugares, ni tampoco sobre la cantidad de retornantes definitivos. La repartición de migrantes y retornantes entre diferentes destinos solamente se ha podido deducir en una forma aproximativa del conjunto de entrevistas realizadas entre los migrantes retornantes como entre los familiares de migrantes ausentes en los dos pueblos. 
la gran urbe. Fuera de los numerosos sancarlinos que siguen sus estudios superiores en Lima, muchos de ellos empiezan allí más a menudo a ocupar empleos dependientes poco calificados y mal pagados, a la diferencia de los cusipateños que, a pesar de empezar también como dependientes no calificados, lo hacen más como ayudantes socios de parientes que son pequeños negociantes o artesanos informales para seguir después como pequeños empresarios independientes. A la diferencia de lo que se nota entre los sancarlinos, los retornos definitivos son más frecuentes entre los cusipateños que se han establecido en el centro regional próximo de Cusco que entre aquellos que se establecieron en Lima o también en Arequipa, un centro regional a la vez más alejado y más importante que Cusco. Esto puede ser relacionado con las perspectivas más reducidas de trabajo o de negocio combinadas con una estratificación y una discriminación mayores en Cusco que en los suburbios de Lima, de Arequipa o que en los centros regionales norteños. En particular, el eje norteño entre Chiclayo y la cuenca amazónica, pasando por Pedro Ruiz, presenta más perspectivas de crecimiento de actividades en un contexto histórico menos caracterizado por la jerarquización y la discriminación socio-étnicas.

Los migrantes sancarlinos, al regresar definitivamente, esencialmente de Lima como lo hemos visto, reanudan con ocupaciones tradicionales, reactivando sus lazos sociales anteriores en el pueblo, pero sin emprender actividades innovadoras y sin tomar responsabilidades preeminentes en el pueblo, sean de orden político o ritual. En cambio, varios migrantes cusipateños que regresaron de manera permanente, y eso, lo repetimos, mayormente de Cusco y no de Lima, lo hicieron con algún proyecto inmediato de cambiar su modo de producir, algunos de ellos también participando más activamente en la vida pública del pueblo después de su regreso. En 2005, la alcaldesa era una migrante de retorno de Lima, donde ya había sido activa en los comités de barrio, pero ella pensaba regresar a Lima. Se puede notar sin embargo que los cusipateños que regresaron con proyectos de innovación en el campo productivo, no encontraron éxito, fuera de unos negocios de madera y otros en menor medida, de elaboración y venta de comidas en el paradero de la carretera. Algunos de los retornantes cuya empresa no tuvo éxito volvieron entonces a Cusco, mientras la mayoría de ellos se volvieron a integrar a las actividades productivas tradicionales, y eso después de la muerte del sobreviviente de sus padres cuyas tierras tomaron a cargo.

Fuera de los regresos efectivos, existen algunos proyectos futuros para desarrollar en su pueblo de origen por parte de los migrantes que siguen viviendo afuera, y eso con la idea de valorizar la formación y la experiencia adquiridas en el lugar de inmigración. Pero, eso también es más el caso de algunos cusipateños que viven en Cusco. Piensan establecer en el futuro un pequeño negocio en Cusipata, combinándolo con alguna actividad secundaria en agricultura. Eso es raramente el caso de los cusipateños de Lima o de los sancarlinos en centros alejados, pero sí de los que se establecieron en Pedro Ruiz y, de hecho, no dejaron de trabajar parte del tiempo en su pueblo de origen en unas formas innovadoras, particularmente en ganadería y en explotación maderera, eso a pesar de haber cambiado de residencia. Se nota así una mayor proactividad de algunos emigrados cusipateños en Cusco o sancarlinos establecidos en Pedro Ruiz en relación con su pueblo de origen, que de los otros emigrados, que al contrario, piensan más en atraer a sus familiares en la ciudad que emprender algo en su pueblo originario. Sin embargo, para los migrantes de ambos pueblos, y eso tanto en Lima como en los centros más cercanos, el pueblo de origen queda un refugio potencial en caso de fracaso de cualquier naturaleza, socioeconómico o personal.

Son más fuertes los lazos de los migrantes cusipateños en Cusco y los de los migrantes sancarlinos en Pedro Ruiz con su pueblo originario respectivo que los que existen entre los migrantes sancarlinos en Chiclayo con este último. Eso se debe a la mayor proximidad geográfica de Cusco y de Pedro Ruiz con el pueblo originario. En efecto, los emigrados 
de los dos pueblos pueden, en esos últimos casos, cumplir con sus deberes sociales frente a la comunidad, es decir participar en las asambleas comunales así como en las faenas comunales, y lo hacen. A veces también se hacen remplazar por parientes cercanos, padres o hermano(a)s para conservar así el acceso a los terrenos comunales en su pueblo. Hay que subrayar, sin embargo, independientemente del papel de este factor geográfico de proximidad y del acondicionamiento climático de estaciones menos marcadas en San Carlos, no habiendo allí épocas con menor requerimiento de trabajadores facilitando la circulación de la mano de obra10, la existencia de tradiciones culturales distintas entre los dos pueblos originarias. Aparte del mayor grado de endogamia y de asociación entre grupos de descendencia y territorio en Cusipata, se nota allí también la práctica más arraigada de viajes de larga distancia que en San Carlos, y entonces una mayor propensión entre los cusipateños tanto a mantener un lazo con la tierra como a combinar actividades de lugares apartados como las de la ciudad con las del campo.

Se manifiesta también lazos entre hermano(a)s de ambos pueblos que emigraron hacia distintos lugares, sea en la capital o en distintos centros regionales. Esos lazos se manifiestan en raras ocasiones, eso a través del intercambio de bienes, pero también por visitas y acogidas. A pesar de ser poco desarrollados y de manera desigual, esos lazos reflejan una solidaridad más grande entre los parientes cercanos esparcidos en distintos polos de inmigración que entre los paisanos no emparentados dentro de un mismo centro de inmigración o que entre los migrantes y sus paisanos no parientes del pueblo. La comunidad de aldea queda así en general para los habitantes y emigrantes de ambos pueblos un universo de identificación menos intenso que la familia cercana, a pesar de ocupar un sitio más importante en la vida de los migrantes en centros regionales cercanos.

Pero, en esta última materia, los cusipateños y los sancarlinos se diferencian en algo. Así, si los lazos que mantienen los emigrados de ambos pueblos entre los centros regionales o Lima y su medio de origen quedan concentrados sobre sus parientes cercanos, principalmente entre padres e hijos o entre hermano(a)s, tío(a)s y sobrino(a)s, se nota en el caso de los migrantes cusipateños una preocupación mayor para los asuntos comunitarias del pueblo originario que entre los migrantes sancarlinos. Eso es más evidente entre los cusipateños radicados en Lima que formaron un club de residentes del pueblo que juntan ocasionalmente alrededor de su culto a la santa patrona de su pueblo originario unos fondos para una u otra obra colectiva a la vez urbanística y simbólica en este último. En Cusco, se ha formado muy ocasionalmente una agrupación de estudiantes jóvenes de Cusipata para incentivar obras públicas en su pueblo de origen, pero eso sin éxito notable, según ellos, por la oposición de las autoridades locales que se sentían desafiadas en su poder. No se nota expresiones solidarias y colectivas de ese tipo hacia su pueblo por parte de los jóvenes sancarlinos establecidos en los centros regionales o en Lima. Pero, muchos migrantes sancarlinos y cusipateños, en Lima y en los centros regionales, participan activamente de manera individual en la vida pública ritual del pueblo, donde se encargan frecuentemente de la celebración del santo patrón del pueblo. Los migrantes de los centros

10 La presencia de estaciones marcadas en el pueblo de origen de los migrantes es vista también por Spedding \& Llanos (1999: 184-189) como un factor que facilita el mantenimiento de actividades productivas complementarias a través de un sistema de ida y vuelta entre un pueblo y sus lugares de inmigración. Los autores declaran también que esta complementariedad es mayor en el caso de poder conservar alimentos en el pueblo de procedencia. Se refieren para afirmar eso a una comparación que hacen de las migraciones a partir de dos lugares distintos de Bolivia, respectivamente en la cordillera al norte de La Paz que es caracterizada por la existencia de estaciones marcadas para los cultivos, y en los valles subtropicales o yungas, que no tienen estaciones marcadas para los cultivos y donde la conservación de los productos es de menor duración. Los autores notan una mayor complementariedad productiva por parte de unas mismas personas entre los polos de la migración entre los migrantes procedentes de la cordillera que entre los que proceden de las yungas. 
regionales cercanos, respectivamente Cusco y Pedro Ruiz, toman también a cargo ciertas funciones de carácter político en el pueblo.

Los lazos preferenciales mantenidos por los migrantes de ambos pueblos en las ciudades directamente con su pueblo de origen no parecen transmitirse a sus hijo(a). Esto(a)s último(a)s parecen identificarse de una manera algo más idealizada con el pueblo y la región de sus padres. Conocen a este pueblo esencialmente por viajes de descanso acompañando a sus padres de visita en el pueblo, cuando son jóvenes y por cortos periodos vacacionales. De todas maneras, los hijos de migrantes de cualquier parte que sean no piensan establecerse un día en el pueblo de sus padres y, a pesar de expresar frecuentemente su aprecio para él y su gusto de visitarlo, menos todavía lo hacen. Sin embargo, si los descendientes directos de los pobladores en el mismo pueblo por un lado y de los migrantes por otro lado toman así vías paralelas de vida, la relación colateral entre tíos de la ciudad, tanto regional como capitalina, y sobrinos del campo, mantiene hasta nueva orden un lazo permanente de tipo transgeneracional entre el mundo rural y el mundo urbano. Los migrantes en los centros regionales cercanos se diferencian al respeto de los de los centros urbanos más alejados o centrales por el hecho de que mantienen relaciones más intensas con su pueblo de origen y modos de relaciones más conformes a las tradiciones de un uso polivalente y extenso del espacio y de sus recursos. Eso se verifica más en el caso de los cusipateños que en el de los sancarlinos.

\section{EL CENTRO REGIONAL: ESPECIFICIDADES ORIGINARIAS E INTEGRACIÓN SOCIAL}

Al llegar al centro regional o a Lima, los inmigrantes de los dos pueblos considerados aquí se alojan donde unos tío(a)s o un hermano(a) el tiempo de completar unos estudios o de conseguir un trabajo, antes de alquilar una habitación propia, y finalmente, al constituir su propia familia, de construir su propia casa. Este último lo hacen mayormente en un lugar distinto al de su lugar de llegada según el sitio que encuentran, lo que significa que no hay correspondencia, menos aún en los centros regionales, entre residencia y origen fuera de la presencia de parientes recién llegados. El nivel de comodidades materiales varía algo más entre los cusipateños en Cusco que entre los sancarlinos en Chiclayo, reflejando una estratificación social previa y diferenciada en cada uno de ambos pueblos originarios. Como es el caso también en Lima, los cusipateños en su mayoría mantienen un grado mayor de endogamia casándose con paisanos del mismo pueblo o de unos pueblos vecinos encontrados mayormente en el lugar de inmigración; los sancarlinos, en cambio, forman pareja con personas de varios orígenes, pero excluyendo prácticamente a los costeños o criollos.

Las relaciones sociales originarias entre los migrantes de cada uno de ambos pueblos en los centros regionales, como también es el caso hasta cierto punto en Lima, se limitan casi exclusivamente a relaciones cotidianas entre familiares o parientes cercanos, es decir de primer grado y secundariamente con parientes escogidos de segundo y tercer grado, incluyendo algunos de ellos recién llegados. En el curso de celebraciones familiares como bautismos, matrimonios, y sobre todo entierros, se extiende el nivel de parentesco con el cual uno se relaciona ${ }^{11}$.

11 Las observaciones al respeto que hacen en forma más general para el conjunto de las migraciones entre campo y ciudad Altamirano \& Hirabayashi (1997: 12-16) sobre los reagrupamientos según el origen en los centros urbanos no parecen verificarse en los centros regionales fuera de ciertos lazos de parentesco cercanos como padres e 
En los centros regionales, para los migrantes de ningún de los dos pueblos existen clubes entre los paisanos del mismo pueblo o de un mismo valle o sector regional, no más que celebraciones rituales o actividades sociales entre gente relacionadas a este nivel originario, cuando sí existe en Lima en lo que se refiere a los cusipateños, pero no a los sancarlinos. El club originario de Cusipata en Lima organiza y anima la celebración de la Virgen de la Asunta, patrona del lugar, rescatando elementos de la fiesta que ya no se dan en el mismo pueblo, organiza encuentros deportivos con bailes, y constituye también una asociación de seguro en caso de enfermedades, accidentes o defunciones para sus miembros. Es este mismo club que sirve de fuente de apoyo para algunas obras colectivas en el pueblo. Hubo una agrupación originaria en el caso de estudiantes oriundos de Cusipata en Cusco; pero, fue efímera e incluyó compañeros de distintas orígenes; se organizó exclusivamente con un fin específico y puntual, la de conseguir precios rebajados para estudiantes en el transporte público de la ciudad. Ya notamos también que, en relación con el pueblo originario, unos jóvenes paisanos cusipateños de Cusco trataron en vano de organizarse entre ellos como con sus parientes en el pueblo mismo para que se realicen ahí ciertas obras públicas.

Fuera de los parientes y de los paisanos (del mismo pueblo o conjunto de pueblos vecinos), existen en los centros regionales como en Lima relaciones preferenciales entre vecinos de distintas orígenes a través de movilizaciones en comités de barrio para emprender tareas o servicios colectivos y concretos. Pero en los centros regionales esos comités de barrio son más efímeros y limitados en el tiempo y en el espacio que en Lima y son más dependientes de la satisfacción de una u otra obra colectiva concreta. Igual que en Lima, esta consiste mayormente en una de las siguientes: la instalación de servicios de distribución de agua, de electricidad y de alcantarillado, el arreglo de las calles, el servicio de basura y hasta los trámites colectivos para legalizar las propiedades de las parcelas ocupadas como la organización de vigilancia para defender la seguridad pública, en particular contra los robos. Por otra parte, los vecinos de una calle también organizan comidas y bailes ocasionales para juntar dinero con fines de ayudar a uno de ellos, sin consideración de origen, en caso de enfermedad, de accidente o de duelo de este último. La participación en esos comités es más activa y corriente entre los cusipateños que entre los sancarlinos, y eso tanto en los centros regionales como en Lima.

Existen también en Cusco como en Lima, entre algunos vendedores ambulantes originarios de Cusipata y sus vecinos de trabajo en la calle, formas de defensa colectiva de su espacio de trabajo frente a las autoridades municipales o frente a otros vendedores no autorizados por ellos. Algunos cusipateños participan, tanto en Lima como en Cusco, en organizaciones sindicales que no solamente se preocupan de mejorar las relaciones de trabajo, pero que también prestan colectivamente ayuda a sus miembros individuales que sufren una desgracia personal o familiar. Por su lado, algunos sancarlinos radicados en Lima mencionan formas esencialmente ocasionales de ayuda personal entre vecinos de trabajo en caso de enfermedad o de accidente; esas relaciones solidarias a partir del trabajo, sea por vecindad, sea a través de una asociación sindical, poco se nota entre los sancarlinos que residen en centros regionales. Parece que la tradición originaria de los migrantes más que el carácter central o regional del lugar de inmigración determina la existencia o no de sistemas de ayuda social alrededor del trabajo.

hijo(a)s, hermano(a)s, tio(a)s y sobrino(a)s. Pedraza Valverde (1992: 132), en su estudio sobre los migrantes rurales en Cusco, confirma el hecho de que los migrantes no se reúnen según el origen, más bién en función de intereses profesionales comunes, y eso particularmente en materia de seguro social. En cambio, hemos visto que los lazos sociales con el pueblo originario mismo son más seguidos que en el caso de migrantes en la capital, y también más en el caso de los cusipateños que en el caso de los sancarlinos en general. 
En cuanto a los proyectos para el futuro de los migrantes en los centros regionales, aparte de unos deseos ya mencionados de volver a establecerse un día en el pueblo de origen, no se planifica nuevas emigraciones hacia otros lugares. Más bien entre los emigrados recién llegados de Cusipata se manifiesta el afán de independizarse en su trabajo en el mismo lugar de inmigración, y entre los emigrados originarios de San Carlos los planes para una educación en este lugar de los hijo(a)s para que pudieran cumplir una carrera de profesional. Todo eso reproduce más o menos las visiones del futuro que tienen también los migrantes de ambos pueblos en Lima. Además eso expresa que el centro regional no es necesariamente pensado como trampolín para una reemigración, inclusivo en la generación siguiente, hacia Lima u otro lugar, y eso a pesar de la jerarquización de los centros urbanos y de su valorización diferenciada. En cambio el retorno al pueblo de origen, sea de las ciudades regionales (de hecho más frecuente en el caso de los cusipateños), sea a partir de Lima (de hecho más frecuente entre los sancarlinos), jamás queda descartado, y eso a pesar de ocurrir solamente por un juego de circunstancias muy particulares para cada caso.

Los hijo(a)s de los migrantes de ambos pueblos, hijo(a)s sobre lo(a)s cuales no he hecho investigaciones específicas, aparte del cumplimiento de algunas obligaciones familiares, desarrollan en los centros regionales como en Lima lazos sociales distintos de los de sus padres, mayormente con compañero(a)s de estudios o de trabajo y fuera del mundo de los paisanos de sus padres. Lo hemos visto, es esencialmente a partir de las relaciones tío(a)ssobrino(a)s que se renueva dentro del lugar de inmigración el lazo originario en el centro de inmigración y al mismo tiempo entre los polos urbano y rural de la migración, y eso tanto en los centros regionales como en Lima. Pero la llegada de los primos del pueblo originario, más seguida entre los centros regionales y el pueblo que entre Lima y el pueblo, como la mayor articulación en el intercambio de servicios y bienes entre centro regional cercano y pueblo de orígen, refuerza la identificación originaria de los hijos de migrantes y entre los primos, los recién llegados como los citadinos, y eso particularmente en los centros regionales. La identificación al pueblo de origen implica una menor idealización del medio de origen entre los hijo(a)s de migrantes en los centros regionales cercanos, que participan más directamente y más a menudo a la vida social, política y económica del pueblo mismo que en el caso de los hijos de migrantes en Lima o en ciudades más alejadas; allí, la afirmación identitaria es algo más paralela y externa a la de los habitantes del pueblo.

\section{CONCLUSIONES}

Los migrantes a partir de los dos pueblos andinos que han servido de universo para este estudio hacia centros regionales de su entorno parecen a menudo usar esos centros como última etapa de un movimiento más amplio geográficamente y no como un eslabón de una migración hacia la capital o el extranjero.

En el centro regional constituido por Cusco, los cusipateños son menos organizados entre ellos a nivel del común origen al nivel del pueblo que en Lima, mientras los sancarlinos son poco organizados a este nivel tanto en los centros regionales como en Lima. Pero, a la diferencia de muchos migrantes en la capital, y sobre todo de los sancarlinos radicados allí, los migrantes de ambos pueblos a centros regionales cercanos no renuncian a sus derechos sobre la tierra originaria cercana. Si confían provisionalmente esos derechos a sus coheredero(a)s, mayormente hermano(a)s, varios migrantes cusipateños en Cusco como también sancarlinos en Pedro Ruiz combinan de hecho actividades agropecuarias tradicionales en su pueblo con actividades asalariadas o comerciales de la ciudad, lo que no hacen los otros emigrados de ningún de los pueblos en lugares más alejados, como la 


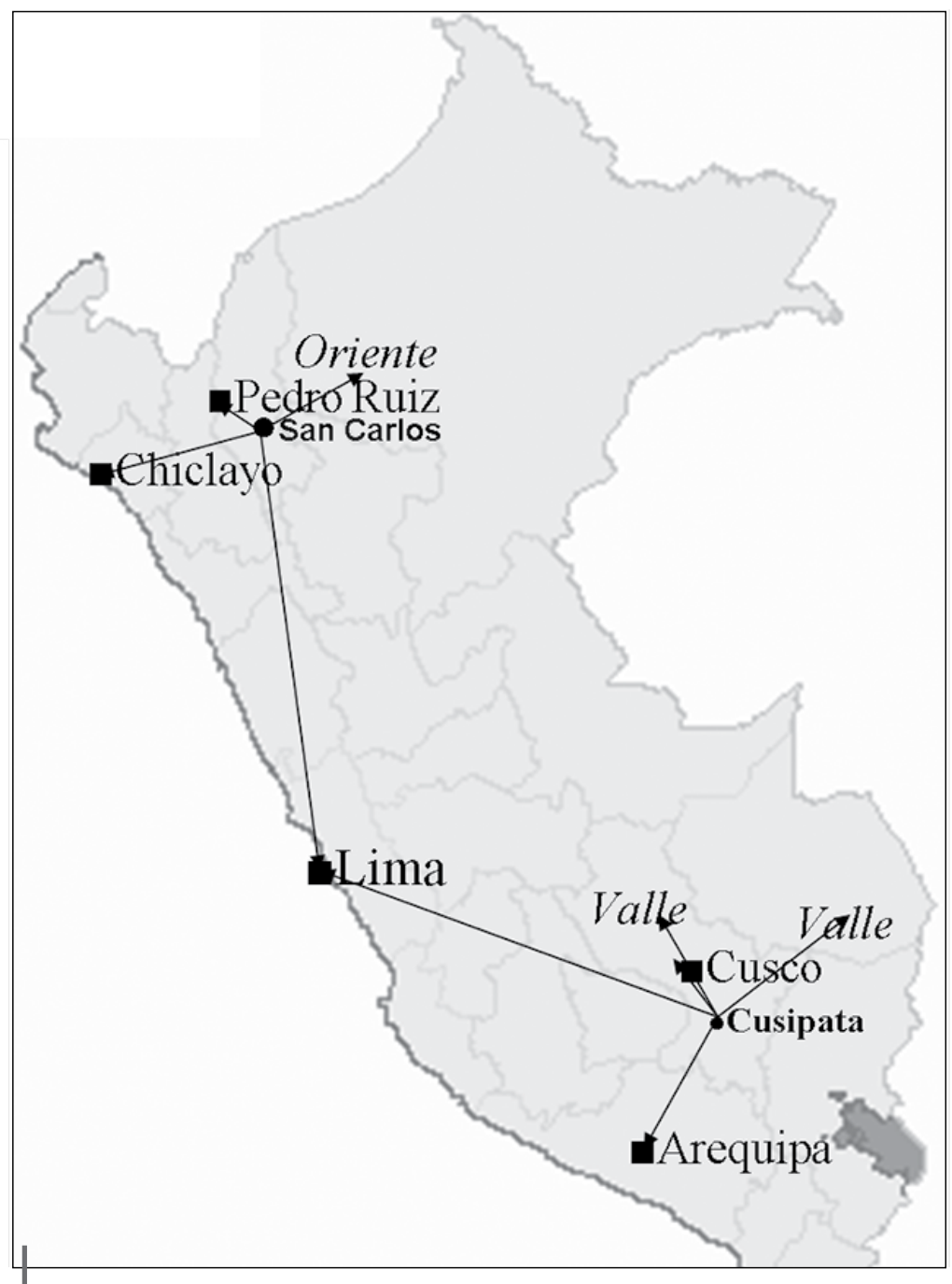

Figura 2 - Migraciones a partir de San Carlos y de Cusipata hacia sus distintos destinos

capital Lima. Realizan así un intercambio intenso de servicios y bienes complementarios entre el centro regional y el pueblo originario. Comprometen para esas actuaciones a familiares (padres y hermano(a)s), pero también implican a otros parientes como tío(a)s o primo(a)s en caso que eso(a) sean sus coherederos(a) a cargo de sus tierras. Eso refuerza las redes sociales de parentesco que se originan en los pueblos de emigración pero tiende a fragmentar el espacio social comunitario o extrafamiliar. Pero muchos migrantes a los centros regionales cercanos participan más también en las actividades políticas y rituales de su pueblo originario que lo hacen los migrantes en lugares más alejados, siquiera para conservar sus derechos colectivos a los recursos comunales a su alcance. Eso limita la fragmentación comunitaria pero crea una discrepancia en términos de poder entre les 
emigrados, a veces más pudientes, a favor de esos últimos, y los habitantes rurales que permanecieron en el pueblo.

Entonces, lejos de expresar a la vez un distanciamiento social hacia el medio originario y una recreación paralela de lazos originarios entre migrantes, como se nota más en Lima, los migrantes en centros regionales relativamente cercanos a su pueblo de origen, cultivan más sus lazos parentales directamente con este último. Elaboran de esta manera un nuevo mundo rural-urbano interno a su región, pero refuerzan a la vez el tejido social del pueblo y la estratificación social interna a este, y eso fuera de cualquier acondicionamiento étnico explícito.

Se nota por otra parte que en cualquier lugar de inmigración, pero quizás más en Lima que en los centros regionales, tanto para los sancarlinos como para los cusipateños, las normas éticas de solidaridad y de confianza mutua que caracterizan los lazos sociales originarias sirven a menudo de base para un seguro social puntual para cada persona que implica a vecinos de distintas orígenes andinas; también sirve para realizar entre vecinos de distintas orígenes obras puntuales de urbanización. Como en los pueblos originarios también, la organización de las actividades productivas quedan más circunscritas en el seno de relaciones próximas de parentesco.

El reforzamiento y la polivalencia de los lazos rural-urbanos de los migrantes en algunos centros regionales a donde se dirigen a partir de los dos pueblos considerados parecen ligados a la proximidad geográfica de esos centros, pero lo están también, en el caso de los migrantes cusipateños, a una mayor endogamia originaria y una identificación mayor de la ascendencia-descendencia con el territorio, como a una tradición más establecida de migraciones estacionales o circulares fuera de su comunidad de origen. Esos factores se manifiestan al margen de las instituciones nacionales y de las normas sociales mercantiles que están tradicionalmente consideradas como los acondicionamientos de la actuación de los migrantes.

\section{Referencias citadas}

ALBER, E., 1999 - ¿Migración o movilidad en Huayopampa? Nuevos temas y tendencias en la discusión sobre la comunidad campesina en los Andes, 213 p.; Lima: Instituto de Estudios Peruanos (IEP).

ALTAMIRANO, T., 1999 - Nuevas interacciones entre el campo y las ciudades. Anales de la XIII Reunión Anual de Etnologia: 347-351; La Paz: MUSEF.

ALTAMIRANO, T. \& HIRABAYASHI, L., 1997 - Migrants, regional identities and Latin American cities, Society for Latin American Anthropology, 180 p.; Washington D.C.: American Anthropological Association.

DEGREGORI, C. I., 2001 - La dimension culturelle de l'expérience migratoire. In: Cultures et mondialisation : résistances et alternatives : 141-153; Louvain-la-Neuve, París: Centre Tricontinental, L'Harmattan.

GÖLTE, J., 2001 - Cultura, racionalidad y migración andina, 144 p.; Lima: IEP.

GÖLTE, J. \& ADAMS, N., 1987 - Los caballos de Troya de los invasores. Estrategias campesinas en la conquista de la Gran Lima, 241 p. ; Lima: IEP.

LONG, N. \& ROBERTS, B., 1984 -Confederations of Households: Expanded Domestic Enterprises in City Country. In: Peasants, Miners, and Entrepreneurs (N. Long \& B. Roberts, eds.): 217-257; Cambridge: Cambridge University Press. 
MALENGREAU, J., 1999 - Structures identitaires et pratiques solidaires au Pérou. Gens du sang, gens de la terre et gens de bien dans les Andes de Chachapoyas, 378 p.; París, Montreal: L'Harmattan.

MALENGREAU, J., 2004 - Continuidades y reestructuraciones identitarias y solidarias entre provincia rural y Lima metropolitana a partir de dos pueblos andinos. Revista Andina, 38: 181-199.

PEDRAZA VALVERDE, G., 1992 - Los campesinos en la ciudad. In: El Qosqo: antropología de la ciudad (J. Tomoeda \& J. Flores Ochoa, eds.): 109-136; Cusco: Ministerio de educación del Japón, Centro de estudios andinos CUZCO-CEAC.

ROGERS, A. \& VERTOVEC, S., 1995 - The urban context: ethnicity, social networks, and situational analysis, 354 p.; Oxford: Berg Publisher.

SÁNCHEZ, R., ORTIZ, J. \& MARTÍNEZ, H., 1988 - Migraciones internas y sus repercusiones en la sierra peruana. In: Migraciones internas y sus repercusiones en la sierra peruana (H. Martínez, ed.): 87-108; Lima: Asociación multidisciplinaria de investigación y docencia en población (AMIDEP).

SPEDDING, A. \& LLANOS, D., 1999 - «No hay ley para la cosecha». Un estudio comparativo del sistema productivo y las relaciones sociales en Chari y Chulumani, La Paz, 356 p.; La Paz: PIEB.

STEINHAUF, A., 1991 - Diferencias étnicas y redes de larga distancia entre migrantes andinos: el caso de Sanka y Colcha. Bulletin de I'Institut Français d'Études Andines, 20 (2): 93-114.

STEINHAUF, A. \& HUBER, L. 1996 - Redes Sociales en una economía étnica: los artesanos de la costa norte del Perú. Bulletin de I'Institut Français d'Études Andines, 25 (2): 269-281. 